\title{
Experimental Study on Mechanical Properties of Cemented Paste Backfill under Temperature-Chemical Coupling Conditions
}

\author{
Yin Liu (D), Hao Li (D), and Haifeng Wu \\ College Mining and Safety Engineering, Shandong University of Science and Technology, Qingdao 266590, China \\ Correspondence should be addressed to Hao Li; 15762284597@163.com
}

Received 28 May 2019; Revised 21 August 2019; Accepted 2 November 2019; Published 16 November 2019

Guest Editor: Stanislav Seitl

Copyright @ 2019 Yin Liu et al. This is an open access article distributed under the Creative Commons Attribution License, which permits unrestricted use, distribution, and reproduction in any medium, provided the original work is properly cited.

To investigate the effect of temperature-chemical coupling on the mechanical properties of cemented paste backfill, three temperatures $\left(20^{\circ} \mathrm{C}, 35^{\circ} \mathrm{C}\right.$, and $\left.50^{\circ} \mathrm{C}\right)$ and sodium sulfate solution mass concentrations $(3 \%, 5 \%$, and $7 \%)$ are applied to simulate the complex environment in a mine. Uniaxial compressive strength and the CPB stress-strain relationship are investigated by applying stress, and the deterioration mechanism was analyzed theoretically according to physical and chemical reactions. At the same time, a structural model of the CPB deterioration mechanism under TC coupling is constructed. Combined with analysis through X-ray diffraction and scanning electron microscopy, it is shown that ettringite and gypsum are the main erosive substances that destroy the structure of $\mathrm{CPB}$ and that increased temperatures accelerate the chemical reaction. The concentration change consumes calcium hydroxide, changing the relationship between ettringite and gypsum. Sodium sulphate crystallization is the main form of physical deterioration. The continuous load accelerates the inelastic deformation time of $\mathrm{CPB}$, resulting in a large yield deformation process.

\section{Introduction}

With the background of vigorously promoting ecologically friendly construction in China, coal mine filling and mining technology has been promoted as a green mining technology in coal mining and goaf management [1,2].However, the high temperature caused by oxidative heat release, blasting operations, and deep-well mining for underground coal [3-5] along with the stress of overlying strata and deterioration by chemical substances such as acids, alkalis, and salts contained in groundwater cause damage to the structure of cemented paste backfill (CPB). The effect is to reduce or eliminate $\mathrm{CPB}$ effectiveness, which in turn affects the stability of the goaf. Therefore, the experimental study on the mechanical properties of CPB under temperature-chemical (TC) coupling has important theoretical significance and practical engineering value for predicting stability in filling engineering.

The effect of filling and mining is closely related to the structural characteristics of $\mathrm{CPB}$. The structure type of $\mathrm{CPB}$ filled into goaves is of the plain concrete type; there are already microcracks in the internal structure of CPB when it enters a goaf before reaching the coagulation and finalization stage. Under complex geological conditions and environmental factors, CPB should bear the effects of load and geothermal heat, as well as chemical action of the external environment. Owing to the triple damage posed by the TC combination, microdamage to $\mathrm{CPB}$ gradually evolves and expands, finally forming a penetrating crack that leads to structural failure. This results in a sharp drop in the bearing capacity and durability of CPB. Fall et al. and Aldhafeeri et al. [6, 7] used an experimental approach to study the influence of curing temperature and combined effects of temperature and $\mathrm{CPB}$ components on the main mechanical properties of CPB (strength, modulus of elasticity, and stress-strain behavior); results showed that the reaction activity of $\mathrm{CPB}$ is related to temperature and that reaction activity increases with atmospheric temperature. However, the effect of temperature depends on the curing time. The effect of temperature on mechanical properties of $\mathrm{CPB}$ depends on the type of binder, the ratio of water to cement, and the type of tailings. Han and Liu [8] studied the effect of temperature on the microstructure of a hardened paste of cement-slag composite cementitious material and the effect of the mortar's subsequent strength. The results showed that temperature has little effect on the degree of hydration of pure cement but that high temperature $\left(60^{\circ} \mathrm{C}\right)$ reduced the postcompressive strength of the pure cement paste. 
In addition, most mine water in China is rich in sulfates, and the oxidation of sulfur minerals and the use of retarders added into cement slurries raise the sulfate content of CPB. Sulfate causes severe deterioration of CPB through physical and chemical action [9-11]. Feng et al. [12] showed through experiments that sulfate reacted to form an expansion product, ettringite, and damage induced by expansion modifies both the local effective transport properties and linear elastic properties of each microstructure at different depths, thereby potentially altering the rates of sulfate ingress and expansion. On the other hand, physical crystallization of sulfate is also one of the main forms of sulfate attack. Chen et al. and Zhang et al. $[13,14]$ studied microstructure changes of cement paste using semiconductors, XRD, MIP, and X-CT. The results showed that the crystalline sodium sulfate formed by sulfate intrusion creates a cement slurry. The internal structure of the body produces crystal stress, which causes its volume to increase, causing severe deterioration. Xu et al. [15] concluded that external sulfate attack is a progressive degradation process that may cause expansion, cracking, loss of binder cohesion, and increased permeability in cementitious materials. Crystallization pressure theory has often been referred to as the most likely mechanism. Chen et al. [16] concluded that the main factors influencing concrete compressive strength are exposure time, water-cement ratio, and sulfate ions. Among these, sulfate attack had the greatest effect. Abedalrazzaq [17] conducted an empirical study on the effects of crack growth in cement mortar exposed to two sulfate solutions. The testing technique was conducted to measure compressive strength, and ultrasonic pulse velocity (UPV) tests simultaneously determined the stress/strength ratio at which cracks propagated. The results showed that crack propagation takes place in specimens exposed to sulfate solutions at stress/strength ratios higher than those kept in tap water. Yu et al. [18] immersed the cement slurry in different concentrations of sulphate solutions; the test showed that sulphate deterioration was staged. In the initial stage of deterioration, the presence of sulfate had a positive effect on the cement slurry strength, and subsequently these properties changed.

According to previous research, many factors such as sulfate presence, geothermal factors, and rock pressure in a mine water context have significant effects on the properties of $\mathrm{CPB}$. Most studies only considered the mechanical properties of $\mathrm{CPB}$ with respect to a single factor such as temperature or ion concentration. However, $\mathrm{CPB}$ is used in a complex environment of different temperatures, different ion concentrations, and various pressures for each rock layer at the same time. The mechanical properties of CPB are different at different ages [19]; at present, there is a lack of research on the mechanical properties of CPB under coupled conditions of temperature, pressure, and ion concentration. Long-term filling of $\mathrm{CPB}$ in this complex environment causes damage to the internal structure of $\mathrm{CPB}$ and affects the stability of goaves in which it is used. In order to explore the deterioration mechanism of $\mathrm{CPB}$ under these coupled conditions and improve its durability, it is necessary to study the influence of TC coupling on the mechanical properties of CPB. Therefore, based on existing research, we select concentrations of $3 \%$, $5 \%$, and $7 \%$ sodium sulfate solution to simulate the chemical environment of $\mathrm{CPB}$ [20] and apply three temperatures of $20^{\circ} \mathrm{C}, 35^{\circ} \mathrm{C}$, and $50^{\circ} \mathrm{C}$ to simulate the temperature of underground $\mathrm{CPB}$ [21]. The uniaxial compressive strength (UCS) of CPB is tested at $1,3,7$, and 28 days, respectively. The variation of mechanical properties of $\mathrm{CPB}$ under temperature-stress-chemical coupling conditions is investigated, and the deterioration mechanism of $\mathrm{CPB}$ under TC coupling conditions is constructed. The structural model is examined through X-ray diffraction (XRD) and scanning electron microscopy (SEM), two microtest methods, to explain and verify the macroscopic phenomena, providing a theoretical basis for studying the durability of $\mathrm{CPB}$ in mines.

\section{Experimental Materials and Methods}

\subsection{Experimental Materials}

2.1.1. Cement. Cement (no. 32.5) is sourced from Shandong Shanshui Cement Group Co., Ltd., and its main components are shown in Table 1.

2.1.2. Fly Ash. The fly ash is from Huangdao Power Plant, Shandong Province, China. The apparent density is $2040 \mathrm{~kg} /$ $\mathrm{m}^{3}$, and the bulk density is $750 \mathrm{~kg} / \mathrm{m}^{3}$. The main chemical composition is shown in Table 2. The particle size distribution and SEM test are shown in Figure 1.

2.2.3. Coal Gangue. The coal gangue is from the Xinzhuang Coal Mine in Shandong Province, China. The main chemical composition is shown in Table 3 . The particle size ratio is shown in Table 4.

2.2. Preparation of $C P B$. The composition of the $C P B$ was determined based on the principle of reducing the amount of cement needed and utilizing as much solid waste (fly ash and coal gangue) as possible. With these goals in mind, the ratio of the cement, fly ash, and coal gangue was selected to be $1: 4: 6$. Subsequently, water was added to the CPB until the solid content in the final mixture satisfied the requirements for use in mines. In general, a solid concentration of $70-80 \%$ is suitable for gravity- or pumping-driven transport through the pipelines [22]. Cube specimens $70.9 \mathrm{~mm} \times 70.9 \mathrm{~mm} \times 70.9 \mathrm{~mm}$ were produced with a mass concentration of $72 \%$. The measured slump was $20 \mathrm{~cm}$, the initial setting time of the specimens was $4 \mathrm{~h}$, and the final setting time was $8 \mathrm{~h}$.

2.3. Experimental Methods. For more realistic simulation of the mine environment, the prepared test pieces were placed in sodium sulfate solutions with mass concentrations of $3 \%$, $5 \%$, and $7 \%$ in advance, and they were then placed in a constant-temperature curing box at temperatures of $20^{\circ} \mathrm{C}$, $35^{\circ} \mathrm{C}$, and $50^{\circ} \mathrm{C}$, respectively. The curing time was $1,3,7$, or 28 days. Another clear-water fluid was used to create a control group. Hence, a total of 48 treatment conditions were studied with three test pieces for each condition for a total of 144 test pieces. After the corresponding age was reached, the filling test piece was taken out of the incubator 
TABLE 1: The chemical component and mineral composition of ordinary silicate cement.

\begin{tabular}{lccccccccc}
\hline \multirow{2}{*}{ Category } & \multicolumn{4}{c}{ Chemical components (\%) } & \multicolumn{4}{c}{ Mineral composition (\%) } \\
& $\mathrm{SiO}_{2}$ & $\mathrm{Al}_{2} \mathrm{O}_{3}$ & $\mathrm{Fe}_{2} \mathrm{O}_{3}$ & $\mathrm{CaO}$ & $\mathrm{SO}_{3}$ & $\mathrm{C}_{3} \mathrm{~S}$ & $\mathrm{C}_{2} \mathrm{~S}$ & $\mathrm{C}_{3} \mathrm{~A}$ & $\mathrm{C}_{4} \mathrm{AF}$ \\
\hline Content & 21.38 & 4.23 & 3.58 & 66.49 & 0.1 & 59.95 & 12.02 & 5.94 & 13.53 \\
\hline
\end{tabular}

TABLE 2: Chemical composition of fly ash (\%).

\begin{tabular}{lccccc}
\hline Source & $\mathrm{SiO}_{2}$ & $\mathrm{Al}_{2} \mathrm{O}_{3}$ & $\mathrm{Fe}_{2} \mathrm{O}_{3}$ & $\mathrm{CaO}$ & $\mathrm{MgO}$ \\
\hline Content & 53.94 & 30.91 & 2.38 & 6.53 & 0.92 \\
\hline
\end{tabular}

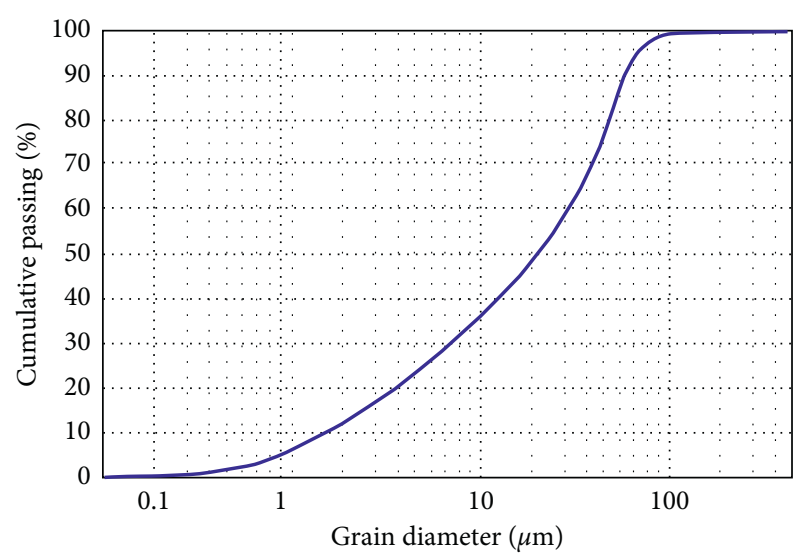

(a)

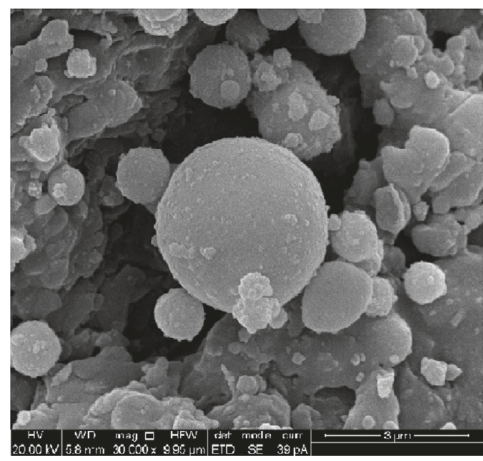

(b)

Figure 1: Particle size distribution of fly ash (a) and SEM image (b).

and immediately loaded in a DY-2008DX automatic pressure-testing machine (load capacity: $50 \mathrm{kN}$ and loading rate: $0.01 \mathrm{~mm} / \mathrm{s}$ ), and only the average value was considered. Owing to the short loading time, the scenario can be approximated as a TC coupled-state loading.

2.3.1. UCS Measurements. The UCS of the CPB was measured using an automatic pressure testing machine (DY2008DX,223 Xianxian Jingqiang Construction Equipment Factory, China; loading capacity $=50 \mathrm{kN}$ and loading rate $=0.01 \mathrm{~mm} / \mathrm{s}$ ). For each curing time, three samples were taken from the curing chamber, and their respective compression forces were measured using the pressure testing machine. The UCS values of the 226 CPB samples were then calculated using
TABle 3: The main chemical composition of coal gangue (\%).

\begin{tabular}{lccccccc}
\hline Composition & $\mathrm{SiO}_{2}$ & $\mathrm{Al}_{2} \mathrm{O}_{3}$ & $\mathrm{Fe}_{2} \mathrm{O}_{3}$ & $\mathrm{CaO}$ & $\mathrm{MgO}$ & $\mathrm{Na}_{2} \mathrm{O}$ & $\mathrm{K}_{2} \mathrm{O}$ \\
\hline Content (\%) & 59.1 & 18.9 & 4.3 & 2.36 & 1.41 & 0.43 & 1.89 \\
\hline
\end{tabular}

TABLE 4: Coal gangue particle size grading.

\begin{tabular}{lccccc}
\hline Size $(\mathrm{mm})$ & +10 & $10-6$ & $6-3$ & $3-1.5$ & $1.5-0$ \\
\hline Content $(\%)$ & 5.18 & 13.68 & 22.55 & 14.97 & 43.62 \\
\hline \multicolumn{5}{c}{$P=\frac{F}{S}}$,
\end{tabular}

where $P$ is the UCS $(\mathrm{MPa}), F$ is the compression force $(\mathrm{N})$, and $S$ is the cross-sectional area of the CPB test sample $\left(\mathrm{mm}^{2}\right)$.

2.3.2. XRD Analysis. Several small blocks were taken from within the $\mathrm{CPB}$ samples after breaking them into small pieces. These small blocks were immersed in absolute ethanol to terminate the hydration reaction. Next, these blocks were dried in vacuum at $55^{\circ} \mathrm{C}$ and ground into powders. These powders were characterized using an X-ray diffractometer (D/MAX-2400, Rigaku Corporation, Japan; scanning range $=5-60^{\circ}$; interval between data points $=0.02^{\circ}$; scanning speed $=4^{\circ} / \mathrm{min}$ ).

2.3.3. SEM Analysis. Several small blocks were taken from within the $\mathrm{CPB}$ samples after breaking them into small pieces. These small blocks were immersed in absolute ethanol to terminate the hydration reaction. Next, these samples were dried in vacuum at $55^{\circ} \mathrm{C}$. Cross sections of the block samples were taken and imaged using an SEM system (JSM$6510 \mathrm{LV}$ JEOL, Japan; magnification $=40 \times$ to $400,000 \times$; accelerating voltage $=50 \mathrm{~V}$ to $30 \mathrm{kV}$, continuously adjustable; tilting angle $=-10^{\circ}$ to $70^{\circ}$ ).

\section{Results and Discussion}

3.1. UCS Test Results. According to the experimental data, the influence curve for TC coupling on the uniaxial compressive strength of CPB is plotted, as shown in Figure 2.

According to Figure 2, the TC coupling condition has a significant effect on the UCS of CPB. There are similar variations at each temperature, roughly divided into two phases: the intensity-increasing phase (before 7 days) and the intensity-declining phase (after 7 days). At the ages of 1 day and 3 days, the UCS increased at any temperature and concentration, and the water control group and the test samples at $20^{\circ} \mathrm{C}, 35^{\circ} \mathrm{C}$, and $50^{\circ} \mathrm{C}$ indicated UCS increases of $18 \%, 25 \%, 29 \%$, and $34 \%, 42 \%, 44 \%$, respectively. The increase of temperature promotes the hydration reaction of cement of lower age, while $\mathrm{Na}_{2} \mathrm{SO}_{4}$ contributes to the 


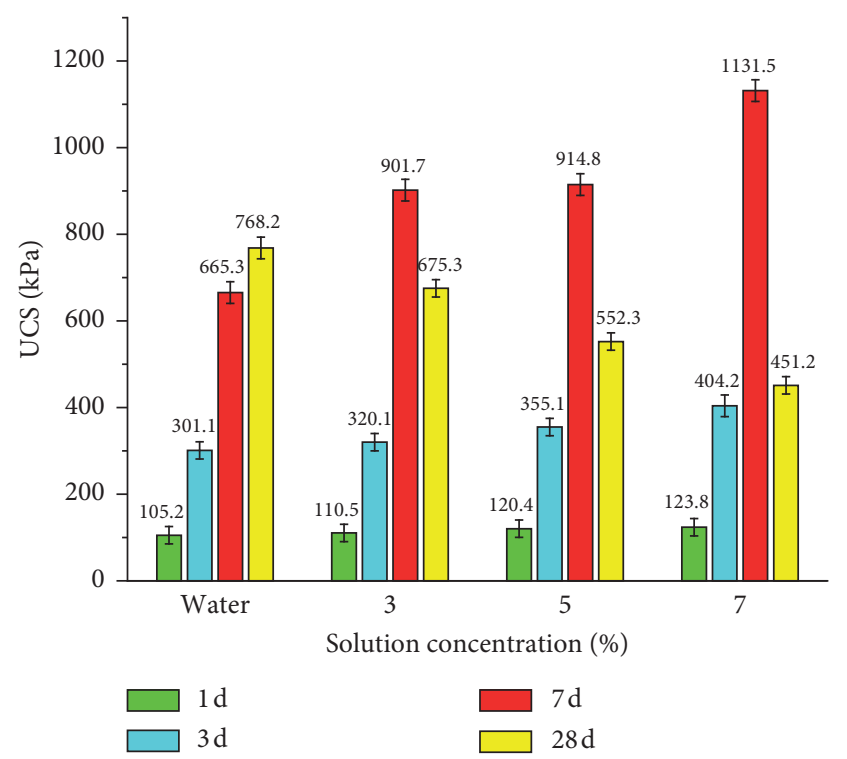

(a)

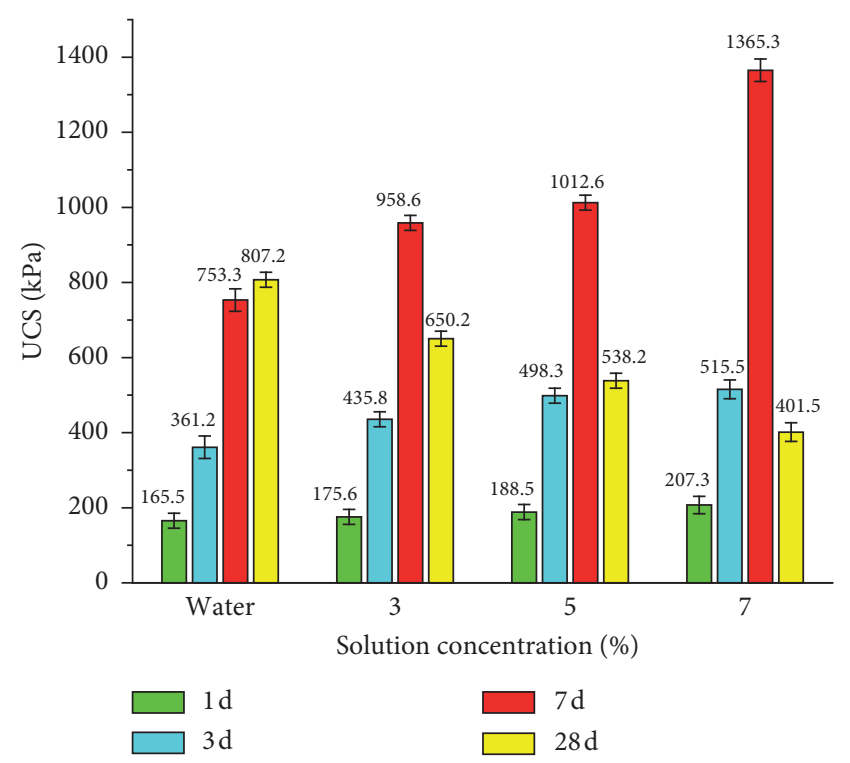

(b)

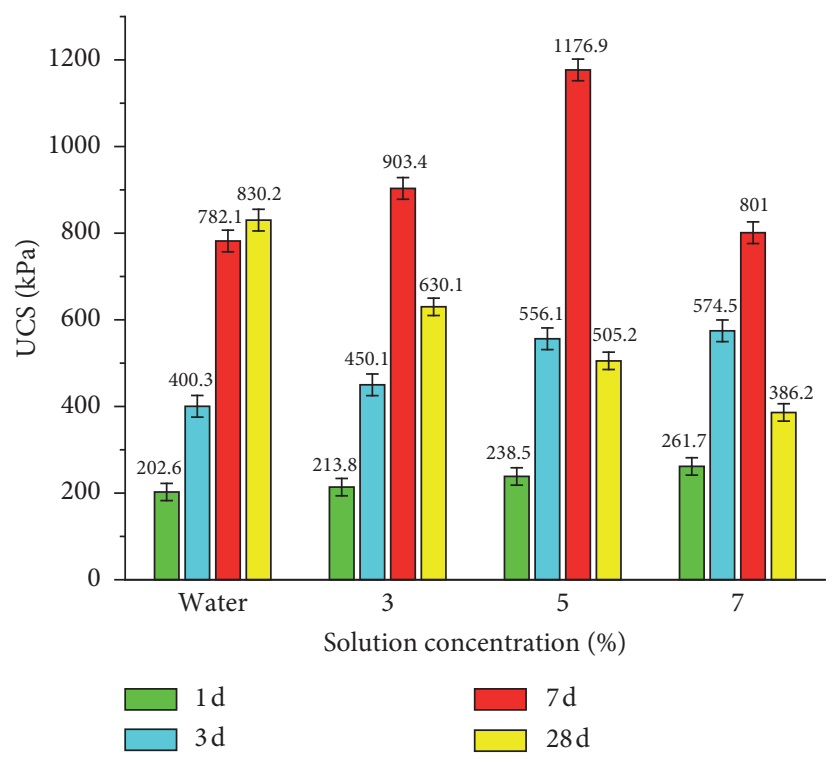

(c)

FIgURE 2: Variation of UCS of CPB under TC coupling conditions. (a) $20^{\circ} \mathrm{C}$, (b) $35^{\circ} \mathrm{C}$, and (c) $50^{\circ} \mathrm{C}$.

strength of $\mathrm{CPB}$ in the early stages [23], resulting in a slight increase in $\mathrm{CPB}$ strength over a short time. However, compared with the results at 7 days, this increase was small.

3.2. Analysis of the Influence of TC Coupling on the UCS of $C P B$. According to the experimental results, the UCS of CPB was in the increasing stage before 7 days, but the increase at 1 day and 3 days was small. This study mainly discusses changes of UCS after 7 days and 28 days for CPB. Following the results shown in Figure 2, the compressive strength after 7 days and 28 days under TC coupling is plotted in Figure 3.

It can be seen from Figure 3 (a) that at $20^{\circ} \mathrm{C}$ and $35^{\circ} \mathrm{C}$, temperature and sodium sulfate concentration contribute to the UCS of CPB. The effect of temperature is more significant as it increases the UCS by $70 \%$ and $81 \%$ compared with the control group. On the one hand, this can be explained by the hydration reaction of dicalcium silicate and tricalcium silicate in cement [24], and a calcium silicate hydrate gel and calcium hydroxide are formed. In terms of filling materials, $\mathrm{CPB}$ does not have a dense structure. In the coagulation and finalization stage, the internal structure of CPB already has pores, and the increase of temperature accelerates the speed of the hydration reaction $[25,26]$. CSH is insoluble in water; it precipitates and gradually aggregates into a gel, which fills the pores between the filler particles and provides early strength to $\mathrm{CPB}$. On the other hand, sodium sulfate reacted with $\mathrm{CH}$ to form gypsum, which subsequently reacts with $\mathrm{C}_{3} \mathrm{~A}$ in the cement to form ettringite [27]. Consumption of $\mathrm{CH}$ by pozzolanic hydration of fly ash also occurs, and increasing temperature promotes the progress of these 


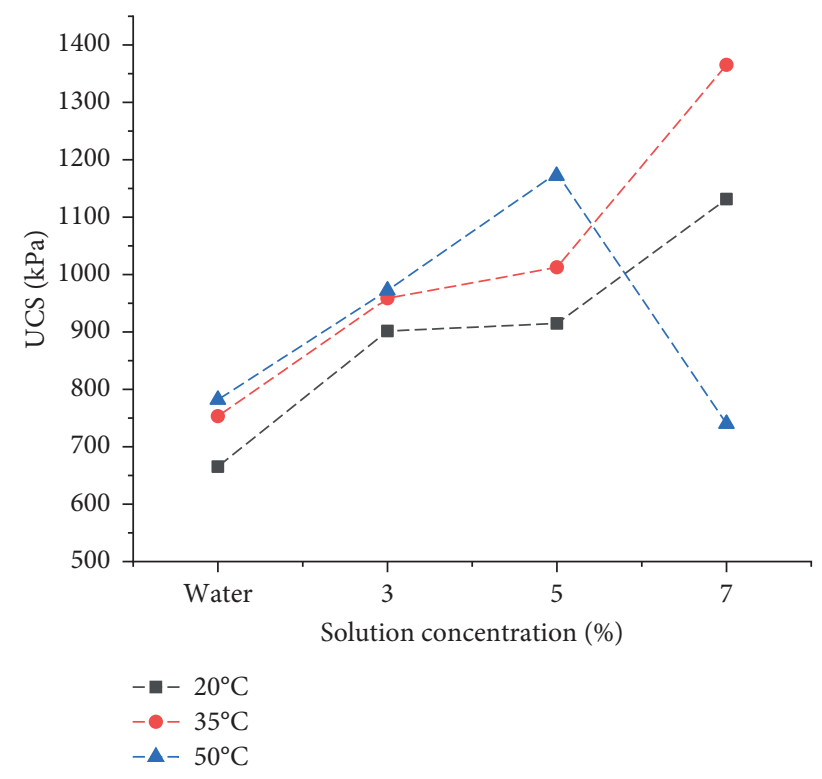

(a)

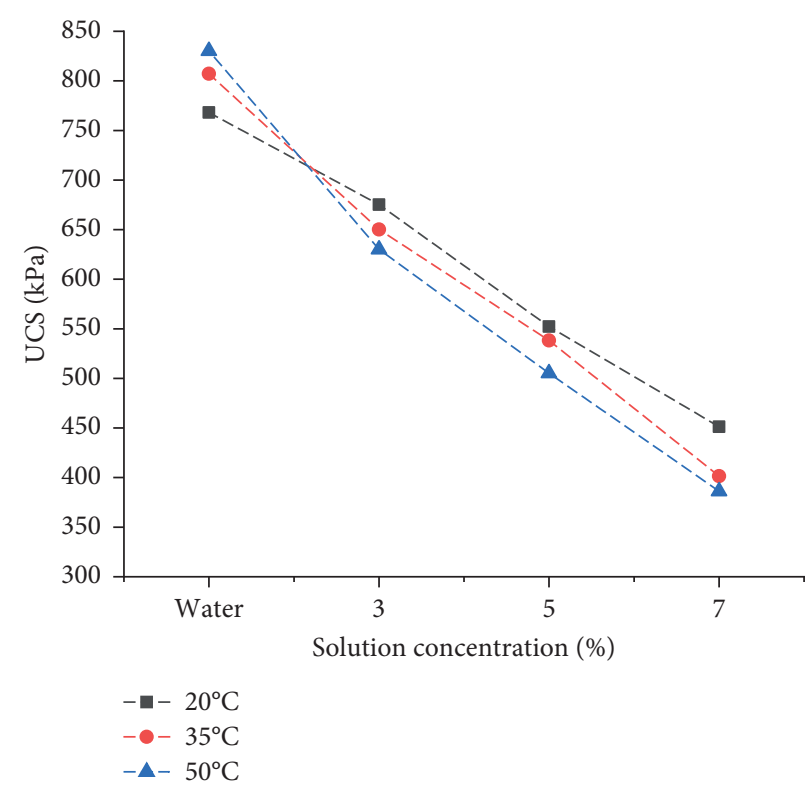

(b)

FIgure 3: Change in UCS of CPB. (a) $7 \mathrm{~d}$ and (b) $28 \mathrm{~d}$.

reactions, thereby producing more hydration products. At 7 days, regardless of what kind of product is formed, it fills the pores of $\mathrm{CPB}$. The amount of the product increases with the concentration of sodium sulfate solution, thereby improving the compactness of $\mathrm{CPB}$. The macroscopic performance shows an increase in UCS.

At $50^{\circ} \mathrm{C}$, the UCS of $\mathrm{CPB}$ changes; its strength increases rapidly when the concentration of sodium sulfate solution is low. At the sulfate level of 5\%, the UCS increased by $50 \%$; when the solution concentration was 7\%, the UCS no longer increased but suddenly dropped by $32 \%$ compared with the results at $5 \%$. The reason for this may be that the temperature was higher, completing the hydration reaction more quickly; when the temperature exceeds $45^{\circ} \mathrm{C}$, ettringite begins to gradually decompose, resulting in increased porosity of the cementitious material, which ultimately reduces the strength of the CPB. Higher temperatures also result in increased adsorption on the sulphate ions in $\mathrm{CSH}$, which can reduce the strength of the $\mathrm{CPB}$. This process was verified through SEM analysis.

It can be seen from Figure 3(b) that, at 28 days, the role of sulfate is more obvious, and the UCS of CPB showed a downward trend in all working conditions. Compared with the control group, the UCS decreased by $41 \%, 50 \%$, and $54 \%$ at $20^{\circ} \mathrm{C}, 35^{\circ} \mathrm{C}$, and $50^{\circ} \mathrm{C}$, respectively. The underlying mechanism of the change in strength was the coupling process between the physical and chemical deterioration, as well as the auxiliary effect of temperature on the deterioration. The reaction between sodium sulfate and $\mathrm{CH}$ was subsequently accelerated and the acicular expansion products ettringite and gypsum were formed. Increased concentration of sulfate results in the formation of more products and generation of greater expansion stress inside the $\mathrm{CPB}$. The stress gradually increases with time, causing the $\mathrm{CPB}$ to crack, thereby decreasing its strength $[30,31]$. On the other hand, the volume expansion is caused by the crystal precipitation of the sodium sulfate solution. The resulting crystalline product can expand the volume by a factor of four [32-34], and the resulting crystalline stress causes the generation of cracks, which ultimately leads to a decrease in the strength of $\mathrm{CPB}$. As the temperature and solution concentration increase, the deterioration of CPB is accelerated, and the process can be further verified by XRD diffraction analysis.

3.3. The Influence of Stress and Strain on CPB under TC Coupling Conditions. Through the comparison of the full stress strain curves obtained by uniaxial compression testing of $\mathrm{CPB}$, it was found that the shapes of the response curves were basically the same and followed the same rules. Therefore, a simplified diagram of the stress-strain curve for single axial compression of CPB is shown in Figure 4.

According to the stress-strain curve for the rock $[35,36]$, the stress-strain process of $\mathrm{CPB}$ is roughly divided into the following five stages: the first stage is the initial deformation stage (OA section). The simplified diagram shows the tendency of the curve to bend upwards, indicating that the slope of the curve is gradually increasing and that the stress of $\mathrm{CPB}$ increases with increasing deformation. This is because, under the action of the load, the cracks and pores perpendicular to the stress direction existing inside the $\mathrm{CPB}$ are closed owing to the pressure. In this process, through the subsidence of the roof and the deformation of the surrounding rock, the $\mathrm{CPB}$ forms a "passive support" for the roof and surrounding rock. Therefore, in the actual filling and mining process, it is necessary to ensure that $\mathrm{CPB}$ is fully connected in order to reduce the deformation of the roof and surrounding rock. The second stage is the elastic deformation stage ( $A B$ section) in which the curve is approximated as a straight line; that is, the slope of the curve is 


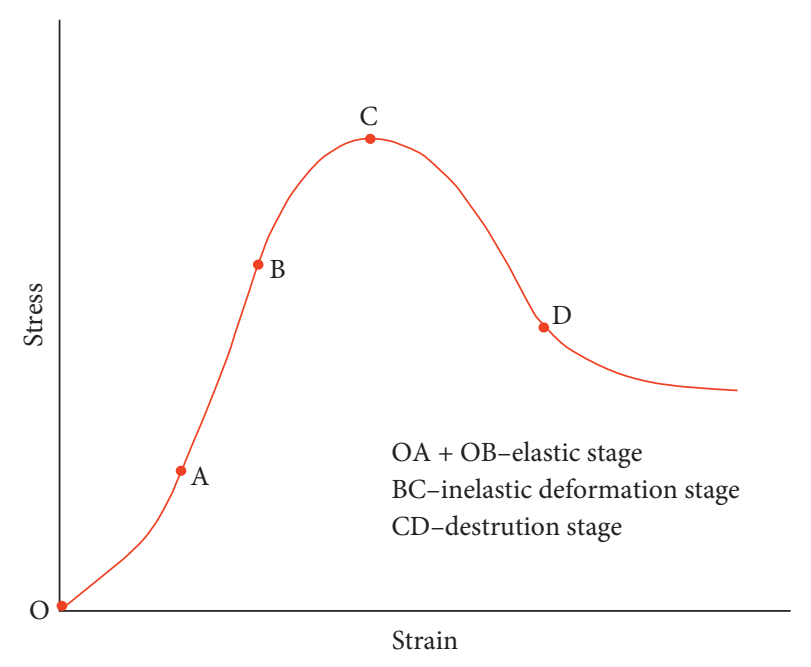

FIGURE 4: Stress-strain curve of CPB under TC coupling condition.

constant in this region, and the strain increases with increasing stress. In this stage, the $\mathrm{CPB}$ has a great supporting effect on the surrounding rock, which can better control the deformation of the roof and surrounding rock. The third stage is the inelastic deformation stage (BC section) in which the curve is bent downward. This stage is the crack extension stage; that is, the slope of the curve is gradually reduced. As the external force increases, the stress field value of the end of the microdefects inside the $\mathrm{CPB}$ reaches its limit value, that is, its peak intensity. During this stage, the support of the $\mathrm{CPB}$ reaches its maximum under the condition of no damage. The fourth stage is the destruction stage (CD section) in which the curve is lowered; this stage is the $\mathrm{CPB}$ failure stage in which the slope of the curve becomes negative. During this period, the UCS of CPB gradually decreases as the strain continues to increase, and its residual strength is reached after reaching point $\mathrm{D}$. Although the inside of the CPB has been damaged to a certain extent at this stage, it still retains a certain residual strength and can withstand a certain load, which is very advantageous for the support of the roof. After the fifth stage, the $D$ point is reached, at which the curve tends to be gentle. This stage is the residual deformation stage of $\mathrm{CPB}$ in which the slope approaches zero. During this period, the UCS of CPB is maintained at a low level as the strain continues to increase, but still reaches $1 / 3$ of the highest strength, exerting a bearing effect to some extent.

According to the test results, the model of the deterioration mechanism of CPB under TC coupling conditions was constructed, as shown in Figure 5. It can be seen from Figure 5 (1) and (2) that, in the absence of sodium sulfate, the hydration of $\mathrm{CPB}$ proceeds normally and that there are many pores present. Under a continuous load, the initial deformation stage $(\mathrm{OA})$ in the stress-strain curve lasts for a long period of time, and the hydration products provide early strength. When the concentration of sodium sulfate solution increases, as shown in Figure 5 (3) and (4), ettringite, gypsum, and hydration products gradually increase in quantity, filling the internal pores of $\mathrm{CPB}$, so that the $\mathrm{CPB}$ structure is more compact. The elastic deformation stage $(\mathrm{AB})$ appears for a longer time in the stress-strain curve, and the corresponding UCS is large. When both the temperature and the concentration of sodium sulfate solution increase, as shown in Figures 3-5 (5), physical and chemical interactions occur simultaneously, and the growth of the crystal product is limited owing to excessive presence of the crystal product. This results in expansion stress, increased internal structure cracks in the packed body, and increased pore diameter. The elastic deformation stage $(\mathrm{AB})$ under the load is small, lasting from initial deformation $(\mathrm{OA})$ to the inelastic deformation stage $(\mathrm{BC})$ and finally to the failure stage $(C D)$.

3.4. Analysis of XRD Diffraction Results. In order to explore the deterioration products of $\mathrm{CPB}$ under TC coupling conditions, the UCS of CPB was sampled, and samples were subjected to XRD diffraction testing. The test results are shown in Figure 6.

After 7 days of deterioration, as can be seen from Figure 6(a), when the temperature is low, ettringite and gypsum diffraction peaks appeared at $2 \theta=11.05^{\circ}, 20.91^{\circ}$, $31.12^{\circ}$, and $39.45^{\circ}$ [37]. This is explained simply by the fact that there are two products of ettringite and gypsum at high sulfate concentrations. The higher the temperature, the more the product fills the inner pores of $\mathrm{CPB}$, improving the UCS. When the temperature reaches $50^{\circ} \mathrm{C}$, the ettringite and gypsum diffraction peaks were greatly enhanced while the $\mathrm{CH}$ diffraction peak was smaller (as shown in the enlarged part) because the higher concentration of sodium sulfate consumed $\mathrm{CH}$. Hence, the formation of the two expansion products of ettringite and gypsum was rapidly increased, thereby generating expansion stress and resulting in a decrease in the UCS of CPB. From Figure 6(b), when the age of deterioration was 28 days, the diffraction peaks of ettringite and gypsum gradually increased with increasing temperature, and there was no $\mathrm{CH}$ diffraction peak at this time, indicating that it was completely consumed by sodium sulfate. In addition, the $\mathrm{Na}_{2} \mathrm{SO}_{4} \cdot 10 \mathrm{H}_{2} \mathrm{O}$ [38] diffraction peak appeared at $2 \theta=22.87^{\circ}$ and $41.48^{\circ}$, and the intensity of the diffraction peak increased with increasing temperature. This indicates that at, 28 days of age, the strength of the filler was further reduced owing to the crystal stress generated by the crystallization of sodium sulfate and the deterioration rate was positively correlated with the temperature and the solution concentration. The quartz and calcium carbonate (calcite) appearing in the figure include quartz contained in the fly ash itself, and may also contain calcium carbonate components brought by sand and stones when grinding the cement slurry $[6,39]$.

3.5. SEM Results Analysis. Since there are similarities in the SEM images at various temperatures, only partial SEM at $35^{\circ} \mathrm{C}$ and $50^{\circ} \mathrm{C}$ are shown.

It can be seen from Figures $7(\mathrm{a}) \sim 7(\mathrm{c})$ that when the solution does not contain sodium sulfate, there are some pores inside the $\mathrm{CPB}$, the product is less, the particles are larger, and the hydration is incomplete. As the concentration of sodium sulfate solution increases, substances such as 


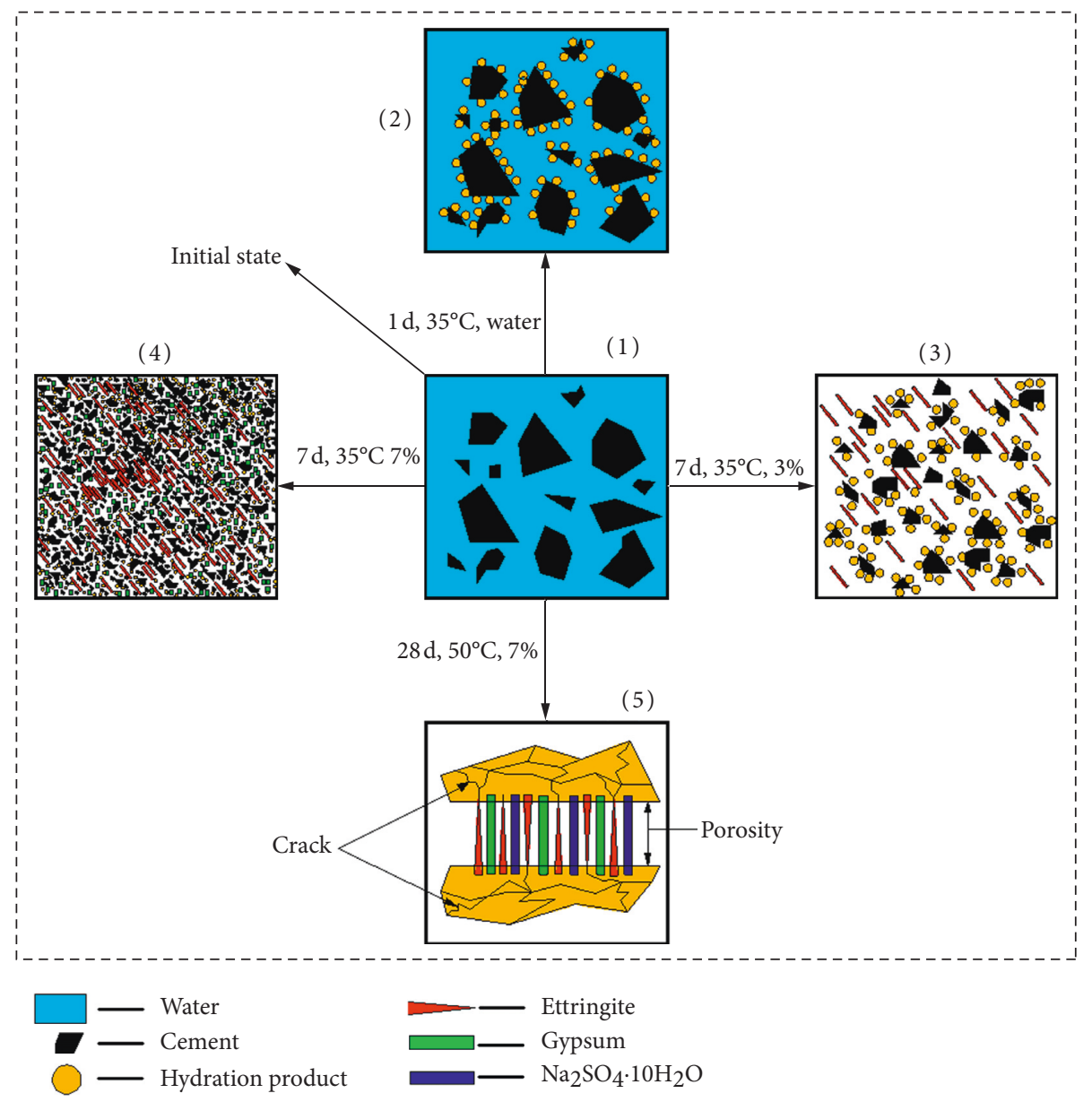

FIGURE 5: Model of deterioration mechanism of CPB under TC coupling condition.

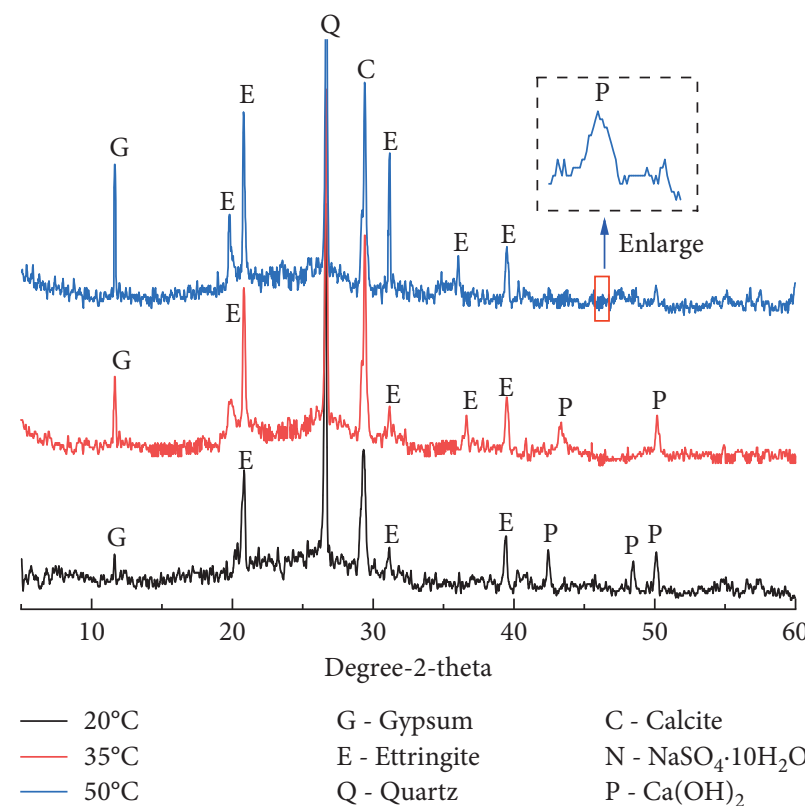

(a)

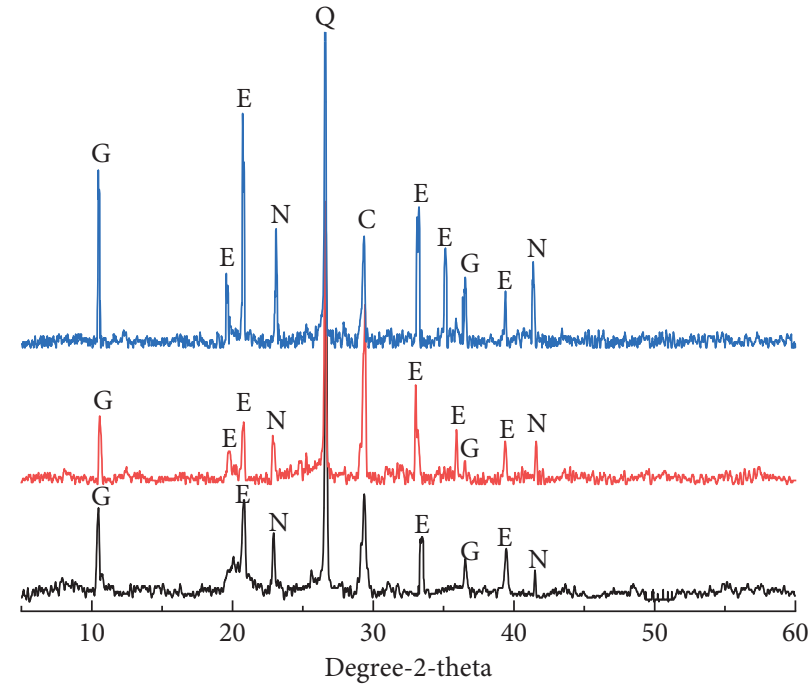

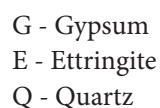

Q - Quartz

(b)

Figure 6: XRD diffraction analysis of $\mathrm{CPB}$ at a solution concentration of $7 \%$ : (a) $7 \mathrm{~d}$ and (b) $28 \mathrm{~d}$. 


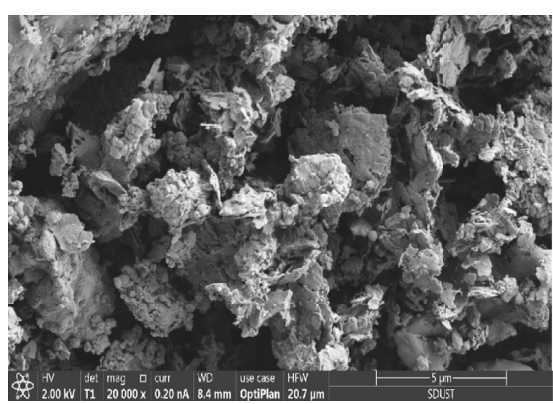

(a)

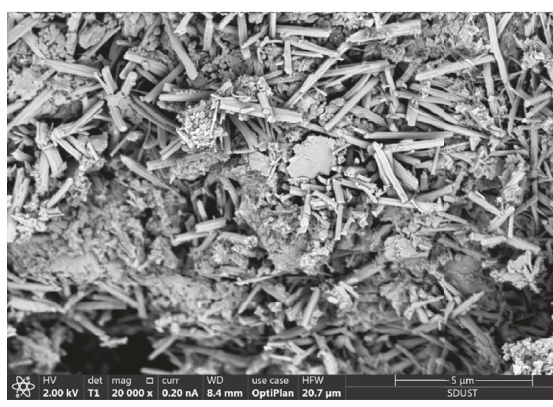

(c)

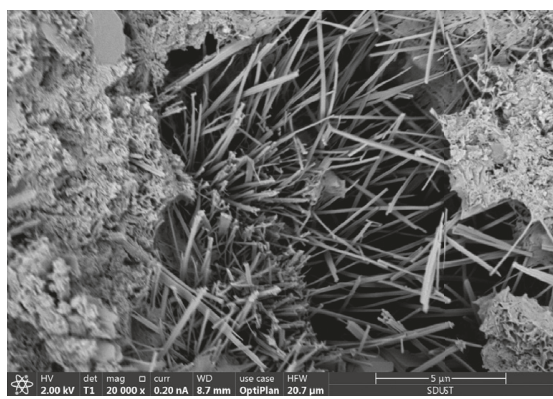

(e)

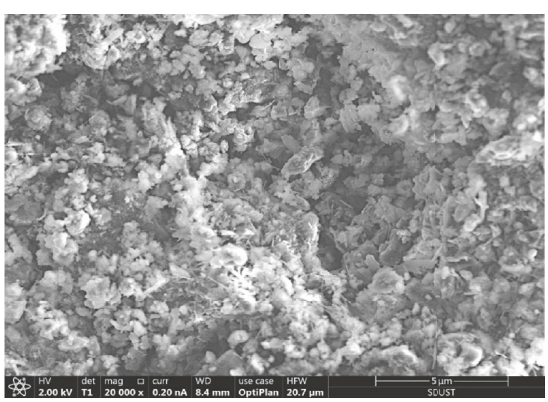

(b)

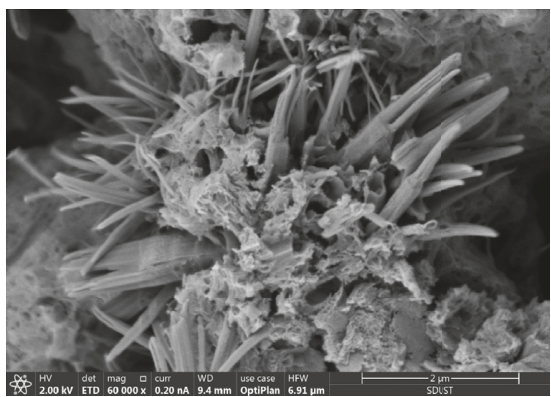

(d)

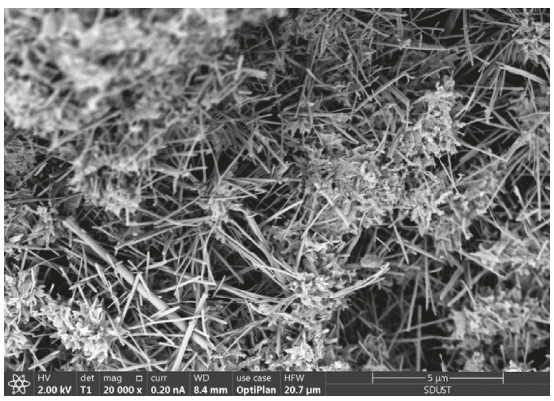

(f)

Figure 7: SEM results. (a) $35^{\circ} \mathrm{C}$, water, $7 \mathrm{~d}$; (b) $35^{\circ} \mathrm{C}, 3 \%, 7 \mathrm{~d}$; (c) $35^{\circ} \mathrm{C}, 7 \%, 7 \mathrm{~d}$; (d) $50^{\circ} \mathrm{C}, 7 \%, 7 \mathrm{~d}$; (e) $50^{\circ} \mathrm{C}, 5 \%, 28 \mathrm{~d}$; (f) $50^{\circ} \mathrm{C}, 7 \%, 28 \mathrm{~d}$.

ettringite gradually increase and fill in the pores of the CPB, which improves the compactness of the CPB. It can be seen from Figure $7(\mathrm{~d})$ that when the temperature and sodium sulfate concentration are higher at the same time, the hydration reaction rate is increased, and sodium sulfate reacts rapidly with $\mathrm{Ca}(\mathrm{OH})_{2}$, resulting in excessive formation of ettringite and gypsum, both of which are expansive. The excessive amount of product will cause expansion stress in the pores inside the CPB and will sporadically grow from the inside to the outside, destroying the internal structure. Due to the short age of deterioration $(7 \mathrm{~d})$, the degree of damage is small. When the age reaches $28 \mathrm{~d}$, as shown in Figures 7(e) and $7(\mathrm{f})$, on the one hand, the expansive product gradually increases in all directions in the internal structure of the $\mathrm{CPB}$, and the expansion stress increases, resulting in an increase in cracks. On the other hand, due to the large pores at the surface of the aggregate and mortar, it is beneficial to the transport of sulfate ions. $\mathrm{Ca}(\mathrm{OH})_{2}$ is consumed in a large amount, and the $\mathrm{pH}$ value inside the $\mathrm{CPB}$ is lowered, and the hydrated calcium silicate cannot be stably existed [40], and the final CPB strength decreased.

\section{Conclusion}

This study investigated the influence of TC coupling on the mechanical properties of $\mathrm{CPB}$. Before 7 days at $20^{\circ} \mathrm{C}$ and $35^{\circ} \mathrm{C}$, thermochemical coupling conditions had no negative influence on the UCS of CPB, and the UCS of CPB increased with the increase of temperature and sodium sulfate concentration, compared with the control group; the compressive strength increased by $70 \%$ and $81 \%$ at $7 \mathrm{~d}$, and the growth rate at $35^{\circ} \mathrm{C}$ was obviously greater than $20^{\circ} \mathrm{C}$. When the temperature was $50^{\circ} \mathrm{C}$ and the concentration of sodium sulfate was $3 \%$ or $5 \%$, the rate of increase of the UCS of CPB was reduced, but was always advantageous compared with the control case of exposure to tap water. When the concentration of sodium sulfate reached 7\%, the UCS decreased significantly, and TC coupling conditions began to have a negative impact on the $\mathrm{CPB}$. When the age reached 28 days, the UCS of the CPB showed a decreasing curve for every temperature and concentration, and the rate of decrease accelerated with increasing temperature and concentration, compared with the control group, $7 \mathrm{~d}$ decreased by $41 \%$ at 
$20^{\circ} \mathrm{C}$, decreased by $50 \%$ at $35^{\circ} \mathrm{C}$, and decreased by $55 \%$ at $50^{\circ} \mathrm{C}$. By analyzing the stress-strain relationship for $\mathrm{CPB}$, the whole process of eroding $\mathrm{CPB}$ under TC coupling was analyzed. There is a certain compression deformation space inside the $\mathrm{CPB}$, and the vertical deformation of the CPB is larger when it is subjected to the action of the roof plate. The TC coupling conditions were further validated for the proposed model of the CPB deterioration mechanism. The erosive mechanism of the deterioration products on the UCS of $\mathrm{CPB}$ was explained from the physical and chemical reactions. Moreover, the relationships between ettringite, gypsum, calcium hydroxide, and $\mathrm{Na}_{2} \mathrm{SO}_{4} \cdot 10 \mathrm{H}_{2} \mathrm{O}$ were clarified by XRD diffraction analysis and SEM analysis of TC coupling conditions. Among these, ettringite and gypsum were involved in the major material chemistry, leading to $\mathrm{CPB}$ structure damage. Additionally, $\mathrm{Na}_{2} \mathrm{SO}_{4} \cdot 10 \mathrm{H}_{2} \mathrm{O}$ resulted mainly from the physical effects of the CPB internal crystallization stress. According to the tests' conclusions, the variation of mechanical properties of CPB under TC coupling conditions is roughly understood, providing a theoretical basis to improve $\mathrm{CPB}$ durability for use in filling engineering.

\section{Data Availability}

All data are available within the article or from the corresponding author upon request.

\section{Conflicts of Interest}

The authors declare no conflicts of interest. The funders will not affect the submission.

\section{Acknowledgments}

The authors would like to acknowledge the Shandong Province Nature and Fund Project (ZR2017MEE055) and Shandong University of Science and Technology, which collectively funded this project.

\section{References}

[1] M. G. Qian, J. L. Xu, and J. C. Wang, "Further on the sustainable mining of coal," Journal of China Coal Society, vol. 43, no. 1, pp. 1-13, 2018.

[2] A. Wu, Y. Wang, B. Zhou, and J. Shen, "Status and prospects of the paste backfill Technology," Advances in Materials Science and Engineering, vol. 2016, pp. 1-10, 2016.

[3] O. Nasir and M. Fall, "Modeling the heat development in hydrating CPB structures," Computers and Geotechnics, vol. 36, no. 7, pp. 1207-1218, 2009.

[4] A. Wu, Y. Wang, B. Zhou, and J. Shen, "Effect of initial backfill temperature on the deformation behavior of early age cemented paste backfill that contains sodium silicate," Advances in Materials Science and Engineering, vol. 2016, Article ID 8481090, 10 pages, 2016.

[5] M. Fall, D. Adrien, J. C. Célestin, M. Pokharel, and M. Touré, "Saturated hydraulic conductivity of cemented paste backfill," Minerals Engineering, vol. 22, no. 15, pp. 1307-1317, 2009.

[6] M. Fall, J. C. Célestin, M. Pokharel, and M. Touré, "A contribution to understanding the effects of curing temperature on the mechanical properties of mine cemented tailings backfill," Engineering Geology, vol. 114, no. 3-4, pp. 397-413, 2010.

[7] Z. Aldhafeeri, M. Fall, M. Pokharel, and Z. Pouramini, "Temperature dependence of the reactivity of cemented paste backfill," Applied Geochemistry, vol. 72, no. 2, pp. 10-19, 2016.

[8] F. H. Han and J. H. Liu, "Effect of temperature on hydration of composite binder containing slag," Journal of Silicate, vol. 44, no. 8, pp. 1071-1080, 2016.

[9] C. N. Shen, D. B. Yang, and X. W. Fang, "Investigation on influencing factors of sulfate attack of concrete," Journal of Water Resources and Architectural Engineering, vol. 2, no. 4, pp. 16-19, 2004.

[10] M. Fall and M. Pokharel, "Coupled effects of sulphate and temperature on the strength development of cemented tailings backfills: portland cement-paste backfill," Cement and Concrete Composites, vol. 32, no. 10, pp. 819-828, 2010.

[11] M. Pokharel and M. Fall, "Combined influence of sulphate and temperature on the saturated hydraulic conductivity of hardened cemented paste backfill," Cement and Concrete Composites, vol. 38, pp. 21-28, 2013.

[12] P. Feng, J. W. Bullard, E. J. Garboczi et al., "A multiscale microstructure model of cement paste sulfate attack by crystallization pressure," Modelling and Simulation in Materials Science and Engineering, vol. 25, no. 6, Article ID 065013, 2017.

[13] F. Chen, J. Gao, B. Qi, and D. Shen, "Deterioration mechanism of plain and blended cement mortars partially exposed to sulfate attack," Construction and Building Materials, vol. 154, pp. 849-856, 2017.

[14] Z. Zhang, Q. Wang, H. Chen, and Y. Zhou, "Influence of the initial moist curing time on the sulfate attack resistance of concretes with different binders," Construction and Building Materials, vol. 144, pp. 541-551, 2017.

[15] M. Xu, S. Erik, N. X. Han et al., "Expansion and degradation of cement paste in sodium sulfate solutions," Construction and Building Materials, vol. 158, pp. 410-422, 2018.

[16] H. C. Chen, C. X. Qian, C. Y. Liang et al., "An approach for predicting the compressive strength of cement-based materials exposed to sulfate attack," PLoS One, vol. 13, no. 1, Article ID e0191370, 2018.

[17] M. H. Abedalrazzaq, "Crack propagation in cement mortar exposed to external sulfate attack," Engineering and Technology Journal, vol. 35, pp. 411-420, 2017.

[18] X. Yu, Y. Zhu, Y. Liao, and D. Chen, "Study of the evolution of properties of mortar under sulfate attack at different concentrations," Advances in Cement Research, vol. 28, no. 10, pp. 617-629, 2016.

[19] A. X. Wu, "Status and prospects of the paste backfill technology," Metal Mine, vol. 481, no. 7, pp. 1-9, 2016.

[20] M. Fall, M. Benzaazoua, and S. Ouellet, "Experimental characterization of the influence of tailings fineness and density on the quality of cemented paste backfill," Minerals Engineering, vol. 18, no. 1, pp. 41-44, 2005.

[21] D. Wu, M. Fall, and S.-j. Cai, "Coupled modeling of temperature distribution and evolution in cemented tailings backfill structures that contain mineral admixtures," Geotechnical and Geological Engineering, vol. 30, no. 4, pp. 935961, 2012.

[22] B. Koohestani, T. Belem, A. Koubaa, and B. Bussière, "Experimental investigation into the compressive strength development of cemented paste backfill containing Nanosilica," Cement and Concrete Composites, vol. 72, pp. 180189, 2016. 
[23] G. X. Yu, Research on the Sulfate Corrosion Performance of Concrete under the Effect of Multi-Factor Coupling (PhD), China University of Mining, Beijing, China, 2014.

[24] R. Krstulovic, "A conceptual model of the cement hydration process," Cement and Concrete Research, vol. 30, no. 5, pp. 693-698, 2000.

[25] L. Raki, J. Beaudoin, R. Alizadeh, J. Makar, and T. Sato, "Cement and concrete nanoscience and nanotechnology," Materials, vol. 3, no. 2, pp. 918-942, 2010.

[26] J. Minet, S. Abramson, B. Bresson, A. Franceschini, H. Van Damme, and N. Lequeux, "Organic calcium silicate hydrate hybrids: a new approach to cement based nanocomposites," Journal of Materials Chemistry, vol. 16, no. 14, pp. 1379-1383, 2006.

[27] M. Benzaazoua, J. Ouellet, S. Servant, P. Newman, and R. Verburg, "Cementitious backfill with high sulfur content Physical, chemical, and mineralogical characterization," Cement and Concrete Research, vol. 29, no. 5, pp. 719-725, 1999.

[28] J. Han, D. Jia, and P. Yan, "Understanding the shrinkage compensating ability of type K expansive agent in concrete," Construction and Building Materials, vol. 116, pp. 36-44, 2016.

[29] K. Liu, L. Mo, M. Deng, and J. Tang, "Deterioration mechanism of Portland cement paste subjected to sodium sulfate attack," Advances in Cement Research, vol. 27, no. 8, pp. 477-486, 2015.

[30] C. Yu, W. Sun, and K. Scrivener, "Mechanism of expansion of mortars immersed in sodium sulfate solutions," Cement and Concrete Research, vol. 43, pp. 105-111, 2013.

[31] M. Wolfram, E. Robin, and D. H. Beddoe, "Sulfate attack expansion mechanisms," Cement and Concrete Research, vol. 52, pp. 208-215, 2013.

[32] R. J. Flatt, "Salt damage in porous materials: how high supersaturations are generated," Journal of Crystal Growth, vol. 242, no. 3-4, pp. 435-454, 2002.

[33] G. W. Scherer, "Stress from crystallization of salt," Cement and Concrete Research, vol. 34, no. 9, pp. 1613-1624, 2004.

[34] H. J. Zhao, Research on the Durability of Sewage Pipe Network Concrete under the Action of Freeze-Thaw Cycles and Sulfate Attack (PhD), Zhengzhou University, Zhengzhou, China, 2017.

[35] C. Z. Zhao, H. Q. Zhou, and Q. D. Qu, "Preliminary test on mechanical properties of paste filling material," Journal of China University of Mining and Technology, vol. 33, no. 2, pp. 159-161, 2004.

[36] B. Yang, Mechanical Properties of High Water Consolidation Filling Body and its Application (PhD), China University of Mining and Technology, 1998.

[37] Q. N. Fei, Microscopic Test Research of Sulfate Attack Concrete in a Complex Environment $(\mathrm{PhD})$, Xi'an University of Architecture and Technology, Xi'an, China, 2013.

[38] G. W. Scherer, "Crystallization in pores," Cement and Concrete Research, vol. 29, no. 8, pp. 1347-1358, 1999.

[39] Y. Wang, M. Fall, and A. Wu, "Initial temperature-dependence of strength development and self-desiccation in cemented paste backfill that contains sodium silicate," Cement and Concrete Composites, vol. 67, pp. 101-110, 2016.

[40] W. Yong, Initial Temperature-Dependence of Mufti-Field Property Correlation and Mechanical Behaviors for Cemented Paste Backfill (PhD), Beijing University of Science and Technology, Beijing, China, 2016. 


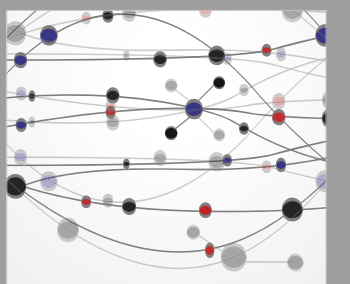

The Scientific World Journal
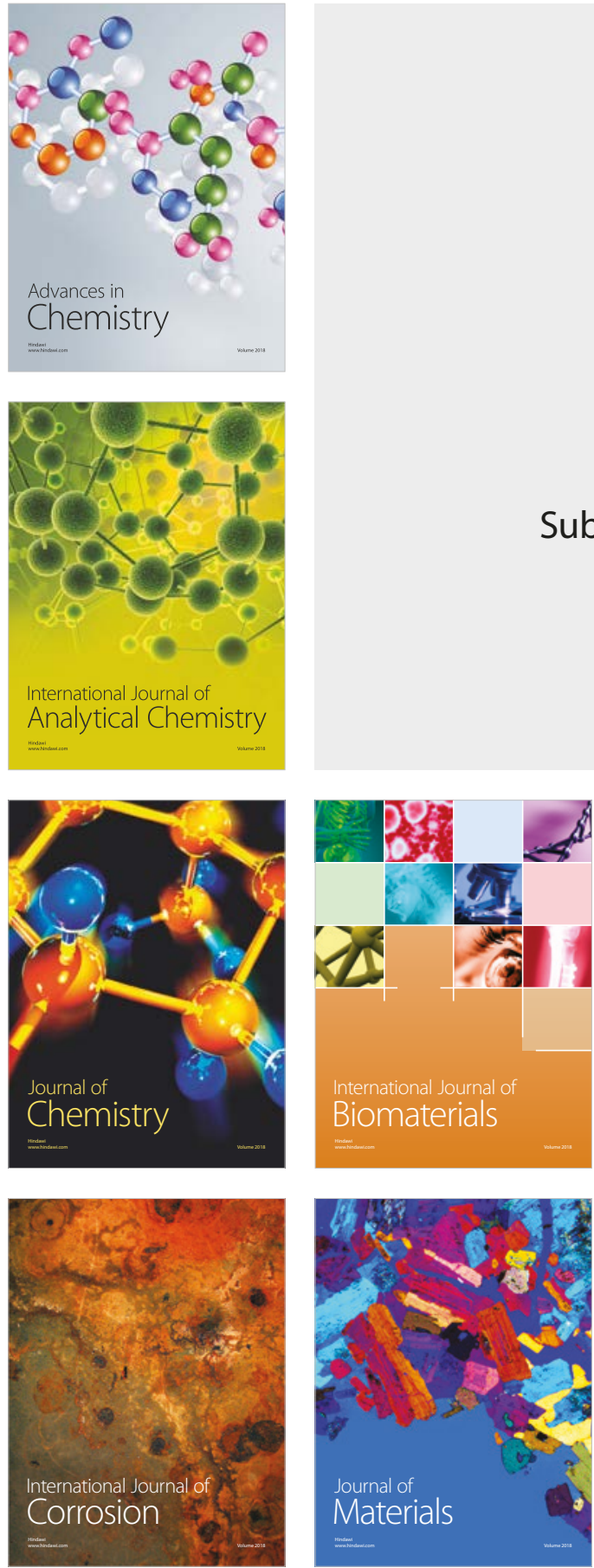

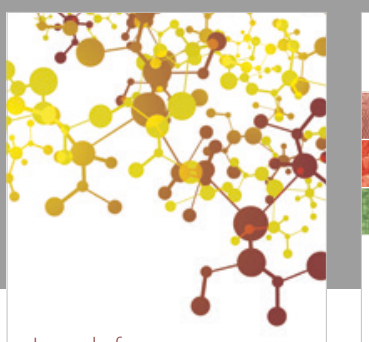

Journal of

Applied Chemistry
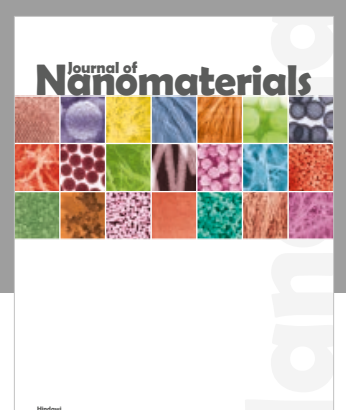

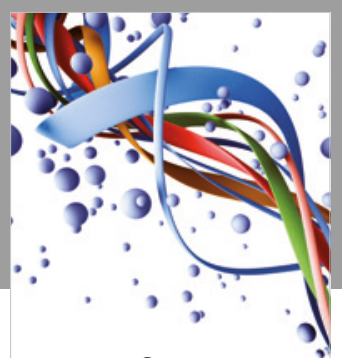

Scientifica

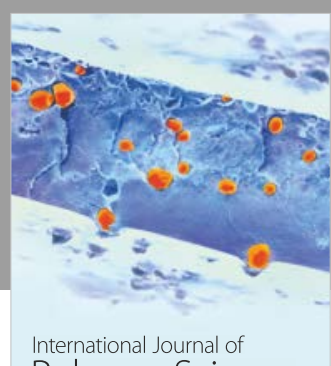

Polymer Science

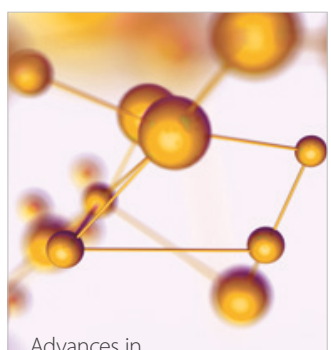

Physical Chemistry
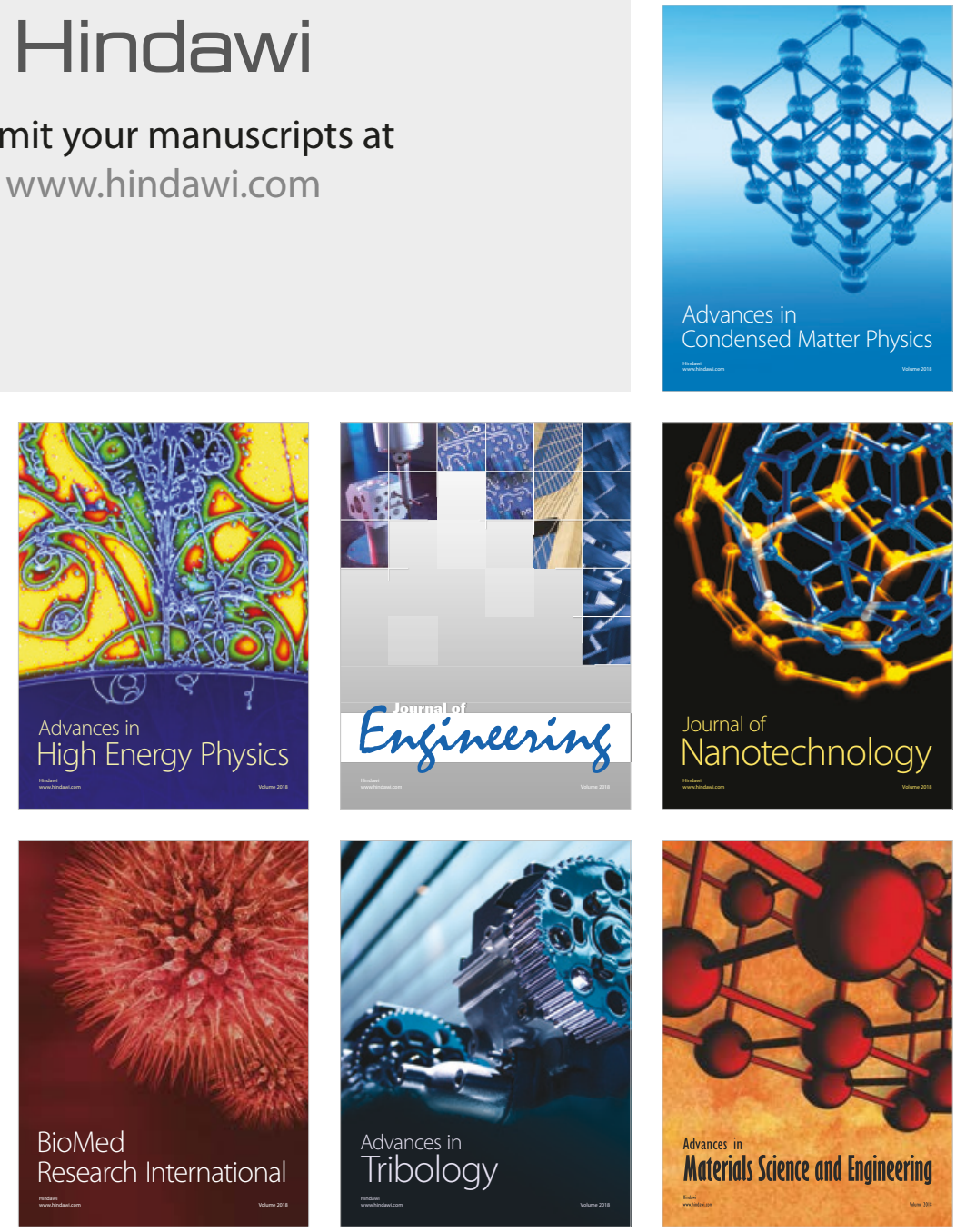